\title{
Social justice and individual ethics ${ }^{*}$ PHILIPPE VAN PARIJS
}

\author{
in Henry S. RICHARDSON (ed.), The Philosophy of Rawls. A Collection of
} Essays. Vol.2: The Two Principles and their Justification, New York \& London : Garland, 1999, pp. 118-142.

It happened to me when bargaining over the price of a hammock on a Mexican beach, when checking my purse in my back pocket on a packed Italian bus and when running into a legless beggar on a Russian souvenir market. It happens to me every year when wondering whether I should report on my tax form the fees or royalties I earned abroad. It happens to me every week when chucking out unread yet another leaflet from yet another charity that caught my name on its mailing list. And it happens to me nearly every day when hearing one of my children ask for more, or nicer, or bigger than what (s)he has already been spoiled with. On all these occasions - and on countless others -, I

\footnotetext{
* This article is a significantly abridged version of a paper that grew, in directions I did not anticipate, out of a sequence of talks given in various places in the course of the academic year 1993-94: at a meeting of the Institut International de Philosophie on "Public and private morality" (Liège, 2 September 1992), at the Philosophy Department of Bristol University (Bristol, 12 February 1993), at the conference on "Democracy and consensus. A debate around John Rawls" (Oxford, 13 February 1993), at the Philosophy Department of the Université du Québec (Montréal, 7 April 1993), et the Legal Theory Workshop of Yale Law School (New Haven, 8 April 1993), at the Séminaire de philosophie contemporaine of the Université catholique de Louvain (Louvain-la-Neuve, 22 April 1993), at the Faculty of economic and social sciences of the Université catholique de Fribourg (Fribourg, 11 May 1993), at the Theology Faculty of the Université de Genève (Geneva, 12 May 1993), at the Philosophy Department of Fu Jen University (Taipei, 29 May 1993), at the Faculty of Sociology and Politics of the Universitat Autonoma de Barcelona (Barcelona, 19 June 1993) and at the 1993 meeting of the September Group (London, 3 September 1993). I am particularly grateful to Bruce Ackerman, Karl-Otto Apel, Christian Arnsperger, Ruth Barcan-Marcus, Brian Barry, Sam Bowles, Chris Bertram, John Broome, Jerry Cohen, Jocelyne Couture, Geneviève de Pesloüan, Toni Domènech, Paul Dumouchel, Ronald Dworkin, Owen Fiss, Marc Fleurbaey, Andreas Follesdal, Keith Graham, Steven Lukes, Adam Morton, Robert Nadeau, Kai Nielsen, Onora O'Neill, John Passmore, Michael Rosen, Dan Weinstock, Erik Wright and above all John Baker and Joe Carens, for stimulating oral and/or written comments. All of them forced me and helped me to think harder about the issues touched upon in the article, but only some of this further thinking found its way into this abridged version. The complete version will appear in the newly founded European Journal of Philosophy.
} 
hit upon the nagging, discomforting question of what, if anything, my professed beliefs about social justice entail for my personal conduct, of what constraints, if any, a person's conception of justice imposes on her personal ethics ${ }^{1}$, or of what it means to be ethically consistent across the political / individual boundary.

In particular - I cannot help asking -, if one is committed - as I am - to some broadly "Rawlsian" conception of justice, is one not also necessarily committed to a broadly "Christian" personal ethics?2 More explicitly, if one believes that justice requires the maximinning of material conditions - however the latter are precisely defined, and possibly subject to the respect of selfownership, fundamental liberties, or the like -, should one not use one's time and resources as well as one can in order to assist the poorest, the most vulnerable - subject, presumably, to not making oneself worse off than them in the process and also possibly, agin, to the respect of other people's fundamental liberties, self-ownership and the like? Or more succinctly, does it make ethical sense to advocate maximin institutions while recoiling from maximin conduct? Can one consistently be a "Rawlsian" without also being a "Christian"?

\section{Managerial dilemmas, utilitarian distinctions}

Those anxious to find reasons to support what I shall call the dichotomic view, i.e. a positive answer to this last question, may first appeal to the following sort of example, which suggests that if you are a Rawlsian, consistency does not only allow you not to be a Christian, but prevents you from being one. Consider the choice of a manager committed to a maximin conception of justice who has to sack one of her workers. Does her commitment to (a lexical version of) maximin demand that she should sack, not her worst worker, for whom it is likely to be most difficult to find another job, but her best worker, for whom this is likely to be easiest. Or suppose she has to hire someone. Should she seek out the person who most needs the job and is likely to be the least employable, the least productive among the applicants? Surely,

\footnotetext{
${ }^{1}$ Here, and throughout the remainder of this paper, "her" stands for "his or her" or "him or her", and "she" for "he or she".

2 As a professor in a catholic University, I may perhaps be forgiven for using this convenient but admittedly parochial formulation.
} 
this inference from maximin at the macro-level to maximin at the micro-level is spurious, as the latter, when consistently practiced, is bound to undermine the former, by gravely impairing the economy's performance, and hence making the best material condition that can sustainably be granted to the worst off considerably worse than is necessary. Far from implying a maximin personal ethics, commitment to a maximin conception of social justice seems to rule it out.

But one should not make too much of this sort of example. For all it does, in the present context, is warn against a naive interpretation of the policy implications of the maximin at both the political and the personal level. If one can sufficiently trust the efficiency of the institutional framework, and especially of its redistributive component, it will generally be best, for the sake of the worst off in our society, if managers do not try, when hiring or firing, when buying or selling, and in any other professional circumstances, to benefit the worst off, but maximize instead their firms' expected profits. However, this does not exemplify a discrepancy between social justice and individual ethics. It simply reflects the fact that the behavioural rule which maximin-designed institutions should impose or which maximin-minded agents should follow in some specific role, need not be maximin itself. ${ }^{3}$ In the same spirit, rule utilitarians are likely to recommend that judges take decisions in line with their convictions about who is guilty, rather than on the basis of their conjectures about which decision would be best for aggregate welfare. What is shown by examples of this sort is not that maximin social justice rules out maximin personal conduct, but that neither must be understood and implemented in too simplistic fashion.

Does the utilitarian tradition not provide a second, and more relevant, type of support to those who would like to cut the link from maximin justice to maximin conduct? True, if you believe that some version of utilitarianism provides the correct answer to the question of how each individual ought to behave, then it is hard to see how you could deny that the same version of utilitarianism provides the criterion in terms of which alternative institutional

\footnotetext{
3 See James Meade's $(1973,52)$ statement that "the ideal society would be one in which each citizen developed a real split personality, acting selfishly in the market place and altruistically at the ballot box" (quoted by Barry 1989, 394-5). Split personalities are not the outcome of a conflict between two moralities, but the instrument of a single one.
} 
setups are to be evaluated. If your individual ethics is utilitarian, how could your conception of justice be anything else? But it does not follow that it is impossible to be utilitarian on the social level - a just social framework is one that maximizes expected aggregate welfare -, while having, for example, a hedonistic life ideal. Indeed, this possibility seems emphatically asserted when utilitarians stress that the content of each person's welfare is "liberally" left entirely open or, even more perhaps, when they want to cleanse people's preferences of any "other-regarding" element the latter may contain in order to avoid the inappropriate discounting or multiple counting of some people's preferences. ${ }^{4}$

On reflection, however, all this can be reconciled with the claim that if we must try to maximize aggregate welfare in the choice of institutions, then we must also do so in our personal conduct. For suppose all members of society are committed utilitarians at both the individual and the social level. If utilitarianism, at both levels, is to avoid unwelcome biases and double counting, it will have to care equally for the satisfaction of every person's selfregarding preferences only: the filtering out of other-regarding preferences at both levels has nothing to do with the separation of the two levels. Moreover, the fact that people's self-regarding preferences, as aggregated by any unbiased utilitarian calculus, can be allowed to vary without limits shows that utilitarianism, at both the personal and the social level, is in some sense "liberal" or "non-perfectionistic". It does not show that the ethical principle that defines appropriate personal conduct can consistently diverge from the one that defines appropriate institutional design, let alone that it must do so.

Thus, despite some appearances, utilitarian distinctions have proved no more able than our managerial dilemmas to support the strong claim that the principles of individual moral behaviour cannot coincide with the principles of social justice. The dichotomic view, however, only makes the weaker claim that the former need not coincide with the latter. This view is forcefully expressed in John Rawls's recent writings.

4 On the former, see the discussion between Scanlon (1991) and Rawls (1993a, 179-80) on whether utilitarianism is a form of liberalism. On the latter, see the discussion between Dworkin $(1977,232-8)$ and, for example, Ten (1980, 30-3) and Ezorsky (1981) on the notion of "personal" preferences. 


\section{Rawls's conception of a well-ordered society.}

According to Rawls's (1971, 453-4) original characterization, a wellordered society is "a society in which everyone accepts and knows that the others accept the same principles of justice, and the basic institutions satisfy and are known to satisfy these principles". Hence, "its members have a strong and normally effective desire to act as the principles of justice require". In so far as the difference principle is concerned, the concrete meaning of this "normally effective desire" is vividly suggested in the connection Rawls (1971, 105) establishes earlier between this principle and "a natural meaning of fraternity": "Members of a family commonly do not wish to gain unless they can do so in ways that further the interests of the rest. Now wanting to act on the difference principle has precisely this consequence." Such formulations strongly support the view that in Rawls's ideal of a just society, maximin does not only shape the institutions, but also guides people's personal conduct.

This is, however, the most fundamental point on which Rawls (1993a, xvi) has changed his position since the publication of his first book. In his more recent writings, he still defines a well-ordered society, the subject of "strict compliance theory", as a society in which "(nearly) everyone strictly complies with, and so abides by, the principles of justice" (Rawls 1990, §5.1). But he stresses that the account of the well-ordered society he offered in A Theory of Justice (TI) was inconsistent. "The fact of a plurality of reasonable but incompatible comprehensive doctrines - the fact of reasonable pluralism shows that, as used in TI, the idea of a well-ordered society of justice as fairness is unrealistic. This is because it is inconsistent with realizing its own principles under the best of foreseeable conditions." (Rawls 1993a, xvii).

To understand this, one needs to see that, according to TJ's account, "the members of any well-ordered society [...] accept not only the same conception of justice but also the same comprehensive doctrine of which that conception is a part, or from which it can be derived" (Rawls 1990, §55.4). But this "fails to take into account the condition of pluralism to which [TJ's] own principles lead" (ibid. §55.5). "Given the free institutions that conception itself enjoins, we can no longer assume that citizens generally, even if they accept justice as fairness [i.e. Rawls's two principles of justice] as a political conception, also accept the 
particular comprehensive view to which it might seem in TJ to belong. We now assume citizens hold two distinct views; or perhaps better, their overall view has two parts: one part can be seen to be, or to coincide with, a political conception of justice; the other part is a (fully or partially) comprehensive doctrine to which the political conception is in some manner related." (ibid. §55.5) Whereas a comprehensive moral doctrine is "one that applies to all subjects and covers all values", a political conception "focuses on the political (in the form of the basic structure), which is but a part of the domain of the moral" (ibid. \$5.3). And it is precisely because commitment to the political doctrine does not entail commitment to the corresponding comprehensive doctrine that realizing the former can be "realistically utopian" (ibid. §5.1, my emphasis). "By contrast, a free democratic society well-ordered by any comprehensive doctrine, religious or secular, is surely utopian in the pejorative sense. Achieving it would in any case require the oppressive use of state power. This is as true of the liberalism of rightness as fairness [the comprehensive moral doctrine corresponding to justice as fairness], as it is of the Christianity of Aquinas and Luther." (ibid. §55.5)

Does this new formulation of the ideal of a well-ordered society provide the dichotomists with the support they are looking for? Does it provide the resources required to resist the entailment from maximin justice to maximin conduct? Certainly not according to a lineage of critics who have accused Rawls of explicitly allowing a far wider range of inequalities than consistency with his own conception should permit. ${ }^{5}$ For this criticism - which has been articulated most recently and systematically by G.A. Cohen (1992a, 1992b) but goes back to Thomas Grey $(1973,316-25)$ in a leftish variant and to Jan Narveson (1976, 7-19) in a rightish variant - presupposes, as we shall see, that such a cut between the two parts of a citizens' overall morality cannot be made, and in particular that strict compliance with a maximin conception of justice must entail maximin conduct. Let us briefly examine the general structure of this line of criticism by focusing on the version offered by G.A. Cohen, before scrutinizing the threat it poses for the dichotomists' stance.

\footnotetext{
${ }^{5}$ I shall return below (section 6) to the question of what does follow for individual conduct, according to Rawls himself, from a commitment to justice as fairness as a purely political conception.
} 


\section{Cohen's egalitarian challenge}

Suppose that everyone is committed to a maximin conception of justice such as the one encapsulated in Rawls's (1971) difference principle. It is commonly believed and said, including by Rawls himself, that even in this sort of context maximin will diverge from equality because the incentives created by income inequalities make it possible to give more to the worst off than the latter would get under strict equality. But why should that be the case ? If I am committed to maximin and could get more than others on the market because of the talents I possess, surely I shall not exploit this possibility and shall accept instead to do the same job for no more pay than the others, thus making it possible (say, through lower prices or higher transfers) to maximize the real income of the worst off without any departure from equality. If everyone's behaviour conforms to the difference principle, the latter will justify no such inequalities. Or, put differently, if you take seriously Rawls's idea that, in a just or well-ordered society, people are committed to the principles of justice that underlie the institutions, then maximin justice demands that incomes be equalized. This is the claim, in its simplest formulation.

But there are two compelling reasons, both acknowledged by Cohen, why this proposition cannot possibly be sustained in this form. Firstly, income on its own does not provide an appropriate metric for a plausible interpretation of the difference principle. This is the case not only because restricting attention to income would lead one to neglect the other dimensions of socio-economic advantages explicitly mentioned in canonical formulations of the difference principle (wealth, powers and prerogatives, the social bases of self-respect), but also, more relevantly, because it would lead one to neglect the unequal distribution of the length and irksomeness of labour. It is in no way inconsistent with a commitment to the difference principle, plausibly interpreted, to say : "I claim more income than others, but no more than what is required to match the burden of doing more hours of work or a more strenuous job" or "I accept less income than others, but on condition that my work load is correspondingly decreased, using some meaningful metric for measuring burdens". Asking whether the difference principle justifies incentive-providing inequalities amounts to asking whether it justifies rewards that go beyond the sheer compensation of arduous work, which can be construed as equalizing unequal situations. Cohen's (1992a, 296-7; 1992b, section 4) claim is that there is no justification for payments to talented people that go beyond this 
compensation and thereby constitute genuine inequalities. The many philosophers who have pondered at length about the fortunes of basketball player Wilt Chamberlain and his younger brother hockey player Wayne Gretsky will need little convincing to believe that such inequalities can still be very considerable.

Secondly, some inequalities may be needed to make it possible (as opposed to attractive) for the talented to perform the job at which they would be socially most useful. I think I can remember, for example, that during the week preceding the Oxford-Cambridge rowing contest, the Oxford University rowing team was hosted by its captain's college and given lavish meals, in order to enable them (not motivate them) to win a victory that would bring great pride to all Oxonians. Similarly, a stressed manager's expensive holidays are arguably needed to enable her and her family to live the sort of life they have to live without going crazy. In such cases, genuine inequality (beyond sheer compensation for doing the job: both the rowers and the manager may actually enjoy it) may be justified, though not justified qua subjective incentives. To use Cohen's (1992a, 311; 1992b, section 8) formulations, such inequalities are "strictly necessary", "necessary apart from human choice", "necessary apart from people's chosen intentions", they reflect "purely objective feasibility sets". Their point is to enable, not to stimulate. Such genuine inequalities, Cohen (1992b, section 4) concedes, are consistent with everyone being committed to the difference principle, but he ascribes them to "special circumstances" and distinguishes them from the "normal case", in which inequalities work as incentives.

\section{Subjective compensation; or the convergence of maximin, equality and self-interest}

What matters to us here, however, is not the empirical question of how much inequality would still find room in Rawls's well-ordered society in the event that Cohen's claim (appropriately qualified) proves valid, but whether the latter is indeed valid. In a society whose institutions are shaped by the difference principle and whose members are committed to it, are the only legitimate inequalities those that are required to compensate for special 
burdens or to generate worthwhile capacities? In other words, do incentive payments have no place in a just society?

To get a better grip on this question, let us try to imagine the functioning of a society that is not only equipped with institutions governed by the difference principle, but also consists in people committed to the latter. Should one, for example, require these people to find out how hard they would work spontaneously in the absence of institutions designed to maximally favour the worst off and then to work just as hard despite the redistributive mechanisms (a rather problematic and underspecified counterfactual exercise)? Or should one require them to be constantly on the look out for the worst off in order to display their generosity? There seems to be a far simpler approach which asks the members of such a well-ordered society no more than a willing and honest participation in the working of appropriately designed institutions. Leaving out, for the sake of simplicity, the possibility of enabling inequalities, one particularly convenient construal of these institutions goes like this. ${ }^{6}$

First, select at random some no-work-some-income option common to all the members of the society concerned, and call it the zero option. Next, ask each person what her reservation wage would be for each occupation (defined by type and length of labour) she could do, and accordingly draw her fair compensation curves, which specify, for each type of labour, the (possibly negative) level of pay required to make that person indifferent between various lengths of labour time and the zero option. Next, determine each person's productivity for each such occupation. Finally, require people to choose occupations in such a way that the social surplus is maximized. The social surplus is here understood as the difference between the aggregate social product (net of capital used up) and the aggregate compensation of those who have contributed to it, as determined by the reservation wages just mentioned. This social surplus is to be distributed equally to all members of the society concerned, thus providing the common zero option. There is of course no reason why the fair compensation curves associated to any particular zero option picked at random should lead to socially optimal assignments that will generate a social surplus per head that matches exactly the chosen zero option.

\footnotetext{
6 The present section and the following two are heavily indebted, more than is acknowledged in the footnotes of this abridged version, to discussions of equality and compensation by Joseph Carens $(1981,1985,1986)$, John Baker $(1987,1992)$ and Brian Barry $(1992)$.
} 
The associated social surplus may fall short of or exceed what is needed to fund this option. The level of income that defines the latter is appropriately chosen when the funds required to finance it exactly match the social surplus generated as a result of people taking up their socially optimal assignment among those they regard as equivalent to the zero option. Within this institutional framework, people's commitment to the difference principle simply requires them (1) to reveal the true pattern of their reservation wages and productivity patterns, so that their fair compensation curves can be worked out and their socially optimal assignment determined; and (2) to willingly accept the latter, as characterized by a particular type and length of labour.

Before turning to the problems the scheme poses, let us note that it painlessly combines maximin, equality and free choice of occupation within each person's legitimate choice set made up of all subjectively equivalent occupations (with appropriate compensatory payments). It even seems able to generate, with choice sets thus shaped, a smooth convergence between commitment to justice and self-interest, the latter negatively defined as whatever, among the things a person cares about, does not reduce to or derive from a commitment to justice. For it suffices to increase very slightly (say, by $\varepsilon$ ) the payment associated with the socially optimal option, for each person to choose out of self interest the occupation which will most contribute to the situation of the worst off, i.e. of everyone, since everyone enjoys a situation equivalent (in her own eyes, and forgetting about the $\varepsilon^{\prime} s$ ) to the zero option. Consequently, this picture of the implied institutional framework seems to fully substantiate Cohen's defensive insistence that he "do[es] not aim to impugn the integrity of a conception of justice which allows the agent a certain self-regarding prerogative" (Cohen 1992a, 314), and that "it is not true that, in the society [he has] in mind, a person would have to worry about unfortunate people every time he made an economic decision" (ibid. 316).

Moreover, the basic setup just sketched can easily be extended from the choice of occupation to the choice of levels of effort within an occupation. Material incentives, and hence inequalities, are not only said to be required to induce the talented to choose occupations which put their talents to productive use. Under the standard version of the so-called efficiency-wage approach to unemployment, for example, the effort is assumed to be a positive function of 
the wage rate because the higher the latter, the greater the fear of being dismissed. If the employer gave the worker no more than the latter's reservation wage, the worker would be indifferent between working and being sacked, and hence would not put as much effort in her work. But here again, if workers are committed to the difference principle, they would reveal truthfully what levels of pay would exactly compensate them for various levels of effort. They could then be told not only what job to do, but also what level of effort to muster (which would not be the maximum feasible one, given the need for compensation), and they would comply, without thereby sacrificing themselves, since they would not be worse off (and could even be made better off by $\varepsilon$ ) than at lower levels of effort.

Furthermore, the same framework can conceivably be extended from working to saving, i.e. to an area which Cohen does not consider but which is no less concerned by claims about the need for incentives. Given some common no-work, no-saving, some-income option, we could then (1) construct for each person the set of combinations of (financially compensated) work and (financially compensated) saving that are equivalent, using her own preferences, to this option, and (2) ask each person (possibly with an $\varepsilon$ signal) to select from this legitimate choice set the combination of work and saving behaviour that maximizes the sustainable social surplus.

Whether in its simpler or in its more complex variant, one striking feature of this egalitarian institutional framework is that it does not require any sacrifice of people's self-interest in addition to the truthful provision of the information the working of the institutions requires. The situation of the worst off will be maximized without any incentive payment (apart from the negligible $\varepsilon$ 's), just as a result of people pursuing their self-interest within the choice set designed for each of them by the institutional framework. The proposal, however, also raises a number of difficulties, at least one of which I believe to be decisive. One essential feature of the proposed institutional setup is that the same type and amount of work (or the same type and amount of saving) will have to be rewarded differently depending on who performs it: the more distaste a person has for contributing to social production in a certain way, the higher the rate at which she will have to be compensated, at least if her contribution is worth having at that rate. 
Clearly, this feature makes the institutional scheme practically unworkable: each worker or saver would need to face a personalized, preference-specific set of wage and interest rates. But at the level of abstraction the present exercise is being conducted, this can hardly count as a decisive defect. More seriously, in order to determine the appropriate differentiation of payments, one needs information that is entirely private: since the self-interest reflected in the fair compensation curves is not definitionally equivalent to the preference schedule that guides a person's choices, there is no way of checking the truth of a person's statements about her reservation wage or interest payments. And this arguably violates the publicity requirement which Rawls and others want any just institutional setup to meet. But above all, the key feature singled out above makes the scheme most questionable as an adequate expression of the egalitarian ideal. For although every person's situation will be, in her own eyes, equivalent to (or, taking the $\varepsilon^{\prime}$ s into account, no worse than) some common baseline situation (the zero option), some people may end up in an objective situation that is far worse, in everyone's eyes, than some others, simply owing to their having more accommodating preferences. Suppose, for example, that you and I can do only the same one job and that, whatever the number of working hours, I resent doing the job more than you do. Consequently, for any given number of hours, the criterion of fair compensation will require paying me more than you. (Surplus maximization may, but need not, ask you to perform more hours than me.) And my assignment (with the associated compensation) is then most likely to be universally preferred to yours. A setup that ends up giving me a universally preferred job because of my being fussier than you - or, to put it differently, because of my having, relative to you, an expensive taste for leisure - is not very credible as an adequate expression of the egalitarian ideal.

\section{Objective compensation; or maximin, equality and self-interest at odds}

Cohen (1992a, 296; 1992b, section 4) is not very explicit about the notion of "special burden" which allows higher remuneration to work as a "counterbalancing equalizer" "where work is specially arduous, or stressful". But the most plausible ways of spelling out the institutional framework called forth by his egalitarian ideal do not rest - if the arguments just stated are cogent, fortunately so - on a subjective notion of fair compensation, as does the 
proposal examined above. Along with Baker (1992, 109-10), he might rather be taken to assume that some objective, individually undifferentiated notion of burden can be used to play the role ascribed above to the subjective, personspecific disutility of working or saving.

The formal structure sketched above then remains relevant: (1) for each level of the zero option, each type of activity and each individual, one draws a fair compensation curve - a set of work-income combinations equivalent to the zero option - which indicates the remuneration needed to cover the special burden incorporated in a certain number of hours of that activity; (2) among these equivalent combinations, people are asked to select the one that maximizes the social surplus (to be distributed equally to all and thereby provide the income entering the zero option); and (3) the zero option is pitched at the highest sustainable level consistent with this process. But because of the objective interpretation of the notion of burden, the implementation of this framework no longer raises the same problems of untractability and lack of publicity - there are no longer different rates of pay depending on some features of a person which only that person can know -, nor the same objection of unfairness - the work-shy no longer get a premium.

But while solving these difficulties, the shift to an objective notion of burden creates another problem, of central importance, as we shall see, for the question of the relationship between maximin justice and individual ethics. ${ }^{7}$ For one can now no longer bank on a guaranteed harmony between the maximal improvement of the situation of the worst off and self-interested choice within the choice sets shaped by egalitarian institutions. Obviously, the various occupations (cum compensation) deemed equivalent by virtue of the objective notion of burden are no longer automatically equivalent according to the agents' preferences. Consequently, it can no longer be taken for granted that picking the surplus-maximizing element in the choice set drawn by the egalitarian institutions will involve no substantial cost, relative to other options

\footnotetext{
${ }^{7}$ I should say that I am exploring this interpretation of the egalitarian ideal because it is present in Cohen's critique of Rawls, not because I believe it provides the most appealing approach. Some metric of opportunities (rather than of income-burden bundles) makes for a better fit with (at least) my moral intuitions, generalizes easily beyond the sphere of production and dispenses with the problematic notion of objective burden (see Van Parijs 1990, 1991). However, some version of the central issues raised in this article arises also under the opportunity-egalitarian interpretation.
} 
in that set, in terms of the person's self-interest. The level of fair compensation associated to various occupations by this objective assessment will in general exceed for some people what is needed to match the disutility incurred, while falling short of it for some other people. Given the choice, the latter's selfinterest may therefore strongly favour the zero option over the zero-optionobjectively-equivalent occupation (for short, ZOE) which surplus maximization would recommend, and this time, therefore, an insignificant $\varepsilon$ would be incapable of reconciling maximin and self-interest by steering people's selfinterested choices in the socially optimal direction. Note, moreover, that this tradeoff would not only arise for those who would be undercompensated, relative to the disutility incurred, if they were assigned to their surplusmaximizing $\mathrm{ZOE}$, but also for those who would then get exactly the right compensation or be overcompensated, as overcompensation may be even greater for some other, non-surplus-maximizing ZOE.

This may seem to point to an unbridgeable conflict between equality, maximin and free occupational choice. If you let people free to choose their occupation, there is no reason to expect that people's choices in their egalitarian choice sets will select the surplus-maximizing option, and maximin will therefore generally diverge from equality. For example, choice-respecting egalitarian institutions seem bound to make you lose the services of an exceptionally gifted manager whose tastes are such that she would be subjectively undercompensated at the rate of pay that matches the objectively assessed burden of a managerial job. Given the choice, she may choose to do no work at all or opt for another, more relaxed occupation (say, being a sculptor) whose objective burden, and hence pay, have been assessed at a lower level but for which she has a far greater liking, so that the lower pay is more than offset by the reduced stress, or by the greater intrinsic pleasure she derives from the job, or by the importance she attaches to her children and spouse no longer having to suffer her being away at unsuitable times. As a result of occupational choice being guided by this preference, exceptional managerial skills are left unused, and both the social surplus and the situation of the worst off remain at a lower level than would have been the case if the absence of free occupational choice had made it possible to effectively assign the sculptor to the manager job instead. 
However, formulating the conflict as one between maximin equality and freedom of occupation begs the central question of this article. For if commitment to the difference principle (whether constrained by freedom of choice or unconstrained) implies accepting the surplus-maximizing assignment, then there is no conflict, in a well-ordered society, between maximin equality and free occupational choice, nor any reason to expect freely choosing but appropriately committed individuals to prevent equality from achieving the maximin. What the example of our managerially gifted sculptor illustrates is rather the possibility of a sharp conflict between maximin equality and selfinterest, even when the choice is restricted to objectively equivalent options. (A graphic illustration is provided in Appendix 2.)

Realizing this possibility forces us to ask the following question: Does the ideal of a just society involve that people should always sacrifice their selfinterest to their commitment to the difference principle, by accepting the surplus-maximizing assignment, however much they would (self-interestedly) prefer another, objectively equivalent occupation? Under the subjective compensation interpretation of equality, the question did not arise. But under the objective compensation interpretation, unless there is a close fit, not just an (uncontroversial) positive correlation, between what people like and what they are good at, it can take a very acute and worrying form. For what people need, if they are to sacrifice their self-interested preferences, is not just a strong commitment to the difference principle, but also a full trust in the way in which the objective burden of the various occupations is being assessed. This puts a lot of weight on the possibility of working out a meaningful objective notion of burden. While it is clear that the latter should not be person-specific, it is also clear that it cannot be completely disconnected from the disutility incurred by the people performing the activity concerned. If everyone prefers doing $\mathrm{A}$ to doing $B$, one cannot sensibly associate a heavier objective burden, and hence a higher level of fair compensation, to the doing of A. But how is this burden to be defined? Perhaps as average disutility, the latter being measured by the reservation wage with the zero option as the only alternative option? But what is the relevant sample? The whole of the active population of the society concerned? Only those among them who have the skills required to do the job? Only those among them who know what they are talking about, because they have had an opportunity to try the job? And what if some would not do the job whatever the wage, thus making the job's average disutility infinite? If simple 
(or more sophisticated) averaging is no good, perhaps we could appeal to some democratic procedure. But even leaving aside the fact that any workable democratic procedure would involve delegating the assessment to an appropriate group of experts, which would take us back to square one, what would be the credentials of majority rule on the presumably factual issue of how burdensome a particular activity is?

I am not claiming that these few remarks make total nonsense of the notion of objective burden. But they suffice to show, I believe, that any such notion is bound to remain conceptually problematic. Consequently, one could never feel on firm ground when turning down the complaint of someone who believes to be unfairly treated, i.e. considers herself unjustifiably made worse off than others in terms of income-burden bundles, as a result of being asked to accept, out of commitment to the difference principle, her surplus-maximizing ZOE. This does not force us to abandon the whole approach. But it seems hard to escape the need to protect oneself against serious injustices by providing every worker with the following sort of safeguard: apart from her surplusmaximizing option, she can also choose, if she prefers, the common zero option to which the latter is supposed to be objectively equivalent.

This seems to be, given the specific interpretation of the egalitarian institutional framework adopted here, a natural way of interpreting Cohen's concession to Scheffler that "every person has a right to pursue self-interest to some reasonable extent" (1992a, 302) or his emphatic refusal "to impugn the integrity of a conception of justice which allows an agent a certain selfregarding prerogative" (1992a, 314). One could of course think of more restrictive or complicated ways of making some room for the pursuit of selfinterest. For example, one could exempt a worker from her socially optimal assignment only if the cost to her of accepting it would be great, and the benefit to society rather small. Or one could imagine that each person would be allowed to pick from a subset of ZOE's involving some contribution on her part rather than to go for the zero option. But apart from its simplicity, the safeguard has the great advantage of meeting what would seem to be a minimum condition of any fair scheme of work compensation, namely that it should make sure that no worker ends up worse off than if she had been left to do nothing. Even those who feel inclined towards more subtle or guarded ways 
of making some room for self-interest should therefore find it worthwhile exploring what follows from introducing the safeguard.

\section{Why incentive payments can be just after all}

But here comes the crux. For once such a safeguard is introduced (arguably as a minimalist way of spelling out Cohen's concession), there is no longer any reason to believe that, in a well-ordered society of suitably committed people (and abstracting, as usual, from enabling inequalities), maximin will necessarily coincide with equality, nor therefore that incentive payments should be ruled out. Once people are left the choice between their socially optimal occupation and the zero option, the (largest sustainable) social surplus and hence the zero option will obviously be smaller than if their choice had been restricted to the former. One way of weakening this negative effect consists in assigning to each worker who would otherwise choose the zero option the socially most beneficial among the ZOE's not blocked by the safeguard. This is no doubt better as far as maximin is concerned, while still being perfectly egalitarian according to the objective metric. But there is better still. It may be possible, consistently with the safeguard, to generate a higher social surplus if people are not only given access to some suboptimal ZOE's, but also to some supra-ZOE's, to some options that are superior to the zero option according to the objective metric. Paying more than the objectively fair compensation may make a productive worker relinquish the zero option in favour of an occupation that will contribute more to the surplus than any of her safeguard-proof ZOE's, despite the additional compensation required.

In the case of the exceptionally gifted but not very keen manager referred to above, for example, it may be better, as far as maximin is concerned, to ask her to be a sculptor rather than remain idle. But it may be even better to provide her with a wage sufficiently high to make her prefer being a manager to doing nothing. For if this higher wage still allows the manager's net contribution to the social surplus to be greater than it would have been with the best ZOE occupation she would have accepted, then, assuming the other workers' compensation is unaffected, social surplus maximization, and hence maximin, will deviate from (burden-sensitive) equality. Ignoring this potential by sticking to payments that do not exceed the assessed objective burden, in 
other words, amounts to keeping the social surplus, and hence the situation of the worst off, lower than it could be. Maximin no longer necessarily coincides with equality once a person's commitment to the difference principle is no longer interpreted as entailing the lexical priority of accepting her surplusmaximizing ZOE over all the other moral and non-moral considerations that make up her self-interest. (See Appendix 3 for a numerical illustration.)

Once this is admitted, incentives of the standard type are not much further down the road. For what has been said so far supposes that one can identify the gifted but reluctant workers and award them the premium required to make them self-interestedly prefer their optimal assignment to the zero option. This supposes in turn that different people may receive different incomes for the same job, depending on the nature of their preferences. This does not take us completely back to the subjective compensation scheme and to the expensive-taste difficulty which proved fatal to it. For paying the fussy more than the keen is now no longer an embarrassing component of the egalitarian ideal, but a by-product of the pursuit of maximin in a context in which self-regarding considerations are allowed to play some role. Nonetheless, this person-specific compensation scheme raises the other difficulties mentioned in connection with the subjective compensation scheme, notably those grounded in its reliance on essentially private information, and this can reasonably be deemed sufficient to discard it.

The alternative consists in conceding the supra-ZOE pay, not only to the reluctant managers, but to any one else doing the same job. While increasing the net contribution of the reluctant manager, the introduction of the premium now also reduces the net contribution of her no less productive but keener fellow managers. This will no doubt make the labour allocator very cautious about awarding any significant premium. It will also further complicate her job, for what was socially optimal for a person to do if she were paid no more than the objectively fair compensation may no longer be socially optimal once she is paid an extra premium. So, instead of adding this further headache to a job that was already unmanageable anyway, the labour allocator may wisely decide to give over to a sufficiently competitive and self-interest-guided labour market the task of allocating people to jobs and determining their gross incomes, while converting herself into a tax collector. The social surplus is then being maximized, not through the filling of jobs and the fixing of wages, but 
through the sustainable-yield-maximizing taxation of every type of job, taking both supply and demand reactions into account, and the equal distribution of this yield.

The two approaches are not quite equivalent. For example, whereas the central allocation method described allows only upward deviations from the ZOE baseline, nothing prevents in principle taxation from turning some jobs which a sufficient number of appropriately skilled workers are keen to do into infra-ZOE's, i.e. occupations paid less than is justified by the objective assessment of the associated burden. Indeed, in the taxation approach, the very notion of objective burden has become superfluous. But I very much doubt this makes any significant difference. Let us bear in mind, in particular, that the equal and unconditional distribution of the surplus guarantees that no worker will be worse off while working than under the zero option. Let us also bear in mind that scarce talents may command large gross incomes as potential employers compete to hire them, but that yield-maximizing taxation should manage to extract the bulk of this factor rent. How much the resulting income distribution would diverge from objective-burden-sensitive equality is of course a question that can only be settled on an empirical basis. But on the plausible assumption that there cannot be that many people who particularly hate doing what they are particularly good at, one can safely conjecture that the income inequalities that would survive yield-maximizing taxation will not be far greater nor far different from those implied by any sensible notion of fair compensation.

In this light, it remains quite possible - indeed, if the facts are not wildly different from what I think they are, extremely plausible - that "a modest right of self-interest [of the sort acknowledged above] seems insufficient to justify the range of inequality, the extremes of wealth and poverty, that actually obtain in [contemporary Britain]" (Cohen 1992a, 302-3). But is the range of inequality thus justified any narrower than the range of inequality allowed by the conventional interpretation of the difference principle? Cohen's concession, as elaborated above step by step, seems to lead to legitimizing all incentive payments that boost the social surplus, and hence the situation of the worst off. Does this mean that people's commitment to the difference principle, once softened by the safeguard, has no impact whatever on legitimate inequalities? Not quite. 
To start with, in the institutional context sketched above, each person committed to the difference principle can be expected to report truthfully her gainful activities and pay honestly whatever tax rates the surplus-maximizing institutions attach to the pay and perks these activities give access to. Being able to bank on this sort of behaviour will enable a well-ordered society to collect and distribute a higher social surplus than would be the case in a society whose members are not so committed. Even in such a society, higher tax rates will induce, owing to the safeguard, lower levels of performance. But they will not widen the gap between actual and reported activities. Thus, safeguardchecked commitment demands that people should not cheat. It also demands that they should not use their bargaining power, especially their collective bargaining power as exercised in strikes and similar actions, in order to resist tax pressure more than they would do by adjusting parametrically to the tax structure, i.e. by simply reducing individually their supply of labour or capital as the tax rate increases. In a well-ordered society, the availability of the highest zero option that can be made available to all provides the legitimate safeguard. Free collective bargaining, or an unrestricted right to strike, cannot be part of the picture. In other words, it is not enough not to cheat the institutions, it is equally important not to bend them. ${ }^{8}$

These are two important features of economic behaviour, whether individual or collective, that follow from a commitment to maximin justice, understood as willing compliance with institutions that aim to maximize the situation of the worst off. But among the choices left open by such institutions and the two constraints on individual behaviour just mentioned, people can and should be left free to pursue their self-interest - broadly understood, remember, as anything that does not reduce to or derive from a concern with achieving justice as characterized, including for example visiting an old aunt or supporting Greenpeace's action in the Antarctic. And if this is conceded, it follows, along the path followed above, that incentive payments - the rewarding of talents over and above what is needed to compensate the

\footnotetext{
8 This twofold restriction on individual behaviour bears at least some resemblance with Rawls's (1990, §37.1) stipulation that, in a well-ordered society, "citizens accept existing institutions as just and usually have no desire to violate, or to renegociate, the terms of social cooperation, given their present and prospective social position. Here we suppose that political and social cooperation would quickly break down if everyone, or even many people, always acted self- or group-interestedly in a purely strategic, or game-theoretic fashion" (my emphasis).
} 
objective burden associated to their productive use (and to make the latter possible) - are legitimate in some quite plausible circumstances, namely in those circumstances in which the sustainable social surplus would be smaller without them, owing to the room granted to self-interest-guided choice.

There will of course be people who will book a substantial "producer's surplus", i.e. enjoy the benefit of a large difference between their actual pay and their reservation pay, as a result of such incentive payments being allowed. But this also happens if the pay matches exactly the assessed burden, as soon as the latter is not defined in terms of person-specific disutility. More seriously, even with perfectly enforced maximin institutions, skills inequalities and/or various obstacles to the clearing of the labour market may well generate situations of dominance, i.e. of unanimous strict preference for one job situation over another or over the zero option. There is no question that these would be genuine inequalities. But once the concern to maximize the objectively worst income-burden bundle is constrained, as a way of making room for legitimate self-regarding considerations, by the possibility of choosing the zero option (or other, socially superior alternatives), then such inequalities are justified. Under perfectly operating maximin institutions, some job situations may be superior to others in everyone's eyes. But any attempt to tax away such universally recognized advantages necessarily leads to a smaller redistributable surplus, as a result of some of the people taxed more heavily legitimately shifting to occupations that yield smaller net contributions to this surplus.

\section{Why most incentive payments are nonetheless unjust, or the unexpected alliance of justice and patriotism}

Even on Cohen's premises, it thus turns out, some genuine incentive payments are justified. But my guess is that the inequalities so justified are of such a modest scope that not only Rawls but also Cohen would feel quite comfortable about condoning them. If this is the case, the apparent clash between left liberalism and radical egalitarianism has melted away. And since there is no point in insisting stubbornly on differences that vanish under scrutiny, radical egalitarians would simply have to shelve their interesting but misguided challenge and rally behind the left liberal flag. Or at least so they would have to do if one could reason, as we have done so far, within the 
boundaries of a closed economy. But once this assumption is lifted, the picture becomes very different indeed. We are then led to considerations that rescue the importance of Cohen's challenge, but also have some other, rather puzzling implications. Let me briefly sketch these considerations and return, by the same token, to our initial question about the implications of a maximin theory of justice for individual ethics.

Suppose first that people can legitimately leave the country with their skills and other assets, if this is what their self-interest tells them to do. The agents' legitimate choice sets are then no longer basically shaped by the fact that the zero option should be available to all and that institutions should maximin people's situations, bearing this safeguard in mind. If agents have the option of supplying their labour and capital abroad and if the country concerned can attract precious factors from the outside world, then, whether or not the other countries each have their own maximin institutions, the situation is deeply altered. For the condition that needs to be met if a person is to choose her socially preferred occupation is no longer that she should regard it as preferable to the zero option (and other ZOE's), but that she should regard it as preferable to the most attractive option abroad. How attractive this possibility is to the person concerned obviously depends on the subjective cost of supplying abroad the factors one owns and on the prices these factors command in other countries, which will in turn depend both on the overall level of development of these countries and on their distributive institutions. Clearly, under such circumstances, just as in the actual world, the owners of potentially mobile and widely valued factors of production will be able to earn, even without any cheating or bending, far higher returns than in the world assumed so far. For the tax elasticity of the supply of these factors (essentially capital and highly skilled labour) tends to be very high, i.e. the amounts of these factors which a country can hope to retain or attract tends to be highly responsive to increases or decreases in their post-tax returns, and the maximin criterion will therefore lead to selecting very low, though yield-maximizing, tax rates.

But is this picture consistent with the assumption that all members of the society concerned are committed to the difference principle? In other words, must disloyalty to one's country be assimilated to cheating or bending, and hence ruled out, or rather to choosing the zero option, and hence legitimized by 
some variant of our safeguard. There is a strong prima facie case in favour of the first answer. If commitment to the difference principle implies that people will not want to cheat by concealing some of their gains in their home country, while still conceivably making a very sizeable contribution to the situation of the worst off in their country through the taxes they pay or the employment they create, then surely commitment to the difference principle must also rule out that people may care so little about their countrymen that they may want to send their capital abroad or to move out altogether with their productive talents in a way that avoids maximin taxation in their home country. In other words, if one is committed to contributing as much as possible to improving the situation of the worst off in one's society, one must a fortiori be committed to sticking with this society - not whatever happens perhaps, but as long as the society's institutions remain just.

This argument, however, cannot be right. For if it were, then it would be even less legitimate to opt for the zero option. At least those who choose to leave the country altogether are not sucking the social surplus. So, if commitment to the difference principle makes it bad to quit, it must make it even worse to get a free ride or, more generally, to get a share in the surplus that exceeds the productive contribution one chooses to make. Or conversely, if a safeguard legitimately protects the desire I may have to surf rather than work, should it not also allow me to move abroad, at a lesser cost to my society, because I fell in love with a foreign culture, a foreign landscape or a foreign woman?

The argument, however, can be rephrased in a way that is not vulnerable to this objection. Let us look at the issue from the standpoint of the original position: we do not know what conception of the good life we shall have nor what talents we shall be endowed with, but we do know which society we belong to. In order to keep our life options open both at home and abroad, we shall certainly not commit ourselves to contributing to the surplus as much as we can. But in order to give ourselves the firmest possible real basis for making any choice we may want to make in case we turn out to have the poorest endowment, we shall not only choose to introduce maximin institutions but also commit ourselves to not cheating nor bending them. These institutions will have to involve the yield-maximizing taxation of incomes earned abroad as 
well as at home, and the matching individual duties will have to require the truthful reporting of foreign no less than of domestic earnings.

Nothing said so far requires that the members of a well-ordered society be subjected to a special duty of patriotism. For the duty not to cheat, and in particular to honestly report any foreign income, seems sufficient to check the downward pressure on the social surplus that would otherwise result from actual or potential international factor mobility. This ignores, however, the crucial question of what defines, for redistribution purposes, membership in the society concerned. Whether it is permanent residence or formal citizenship, it is clear that the duty not to cheat offers only very poor protection against the pressure of international mobility if membership can easily be changed. If the institutions were to prohibit emigration (whether interpreted as a change of permanent residence or of citizenship status), the duty not to cheat would encompass the duty not to emigrate and the problem would disappear. But such an institutional prohibition would clearly violate what Rawls and many others would count among people's fundamental liberties. And so would, presumably, the imposition of prohibitive costs on prospective emigrants, such as the reimbursement of educational expenses, or of the present value of one's skills, to the society they are leaving.

This is why a special duty of patriotism needs to enter the picture. Such a duty does not need to require that one should never use the institutionally guaranteed right to emigrate. What it must require is rather that one should not emigrate for the wrong reason, i.e. modify one's residence or citizenship status in order to enjoy a more favourable tax treatment. What generates strong constraints on the effective operation of an open economy's maximin institutions in a large world is not that its members may want to relinquish their membership because they fell in love with foreign people or foreign landscapes, but only that they may want to do so because of their interest in maximizing their post-tax incomes. If they endorse maximin institutions, it would be inconsistent for the best endowed members of a society not only to consider cheating but also to consider escaping in response to high taxation. For the consequence would be that the objective of the maximin institutions would be defeated: precious little could be collected for redistribution to the worst off, both because of actual cheating or escaping and even more because of credible threats to cheat or escape. Knowing which society they belong to, 
people in the original position will protect themselves against this risk by committing themselves to behaving not only honestly but also patriotically, in the restricted sense of refusing to consider relinquishing membership in their society for the wrong sort of reason.

If the society's members can be relied on not only to refrain from cheating (and bending), but also to refrain from moving out in search of higher returns, then the constraints on the society's attempt to make its worst off members as well off as possible are greatly loosened, and the size of the incentive payments that will sustainably maximize the situation of the worst off will be far smaller than if tax rates had to keep subjecting themselves to the ruthless discipline of a highly responsive world financial market or of an increasingly integrated international market for skilled labour. Of course, how great a loss can be avoided in this way will greatly vary as a function of the size of the territory controlled by the relevant tax authority, of the society's relative prosperity, of the distinctness of its language and culture, of the charm of its climate and countryside, and of many other factors. But the very modest extent to which people actually alter their place of residence or their citizenship in order to avoid taxes should not make us underestimate the impact of potential emigration on the current and, even more, the future shape and size of redistributive policies. The growing asymmetry between the taxation of capital and labour income and the erosion of the progressiveness of income taxation in several countries can plausibly be interpreted as two clear signs of growing pressures in an ever more open - and unpatriotic - world.

One implication of this argument, if it is correct, is that - after all - Cohen is right and Rawls is wrong on the issue of whether (the bulk of) surplusenhancing incentive payments are justified, or at least that Rawls would be wrong if what he had in mind was an open economy in a large world of the sort we live in. In a hypothetical closed economy, whatever incentive payments would be paid to self-interest-guided economic agents under maximin institutions can be justified, because maximin requires them, despite a universal commitment to the difference principle, as soon as self-regarding considerations are allowed to guide people's choice with the zero option as a common baseline. In an open economy, this would not be the case. Some part, and probably by far the greatest part, of the incentive payments paid to selfinterest-guided economic agents under maximin institutions would then 
remain unjustified, because they would only be needed as a consequence of the widespread adoption of an attitude that is inconsistent with a commitment to the difference principle.

\section{Rawlsians: not Christians but patriots ?}

What constraints, if any, does a commitment to maximin justice impose on one's individual ethics? The (very partial) answer we are ending up with can be summed up as follows. Once maximin institutions are in place, commitment to maximin does entail a duty not to cheat or bend these institutions, and strict compliance with this duty will enable the maximin to be far more egalitarian than it would otherwise be. But it does not entail a moral duty to help those poorer than oneself. It is not inconsistent with such a duty, but performance of the latter would be a expression of love, charity or caring, not an implication of a commitment to maximin justice, as we have come to interpret it. In a wellordered society, being committed to the difference principle does not force us to find it despicable or objectionable to spend much of one's time and money collecting Indian totems or supporting the local soccer team, at the expense of doing everything within one's power to improve the situation of the worst off, providing of course the time and money thus used do not exceed what we get allotted by maximin institutions.

To be honest, this negative conclusion is not particularly relevant to the moral choices we face in our daily lives, such as those mentioned in the first few sentences of this article. For we undoubtedly live in a badly ill-ordered society, and this leads to a different set of questions. In such circumstances, could we, for example, allow ourselves to be less honest, less cooperative, less patriotic than we would need to be in a well-ordered society, whether because the institutions are not to be trusted to generate, collect and distribute the social surplus in an efficient way, or because others do not do what the institutions expect them to do? Or should we rather be more demanding on ourselves, for example because it is up to us, in our private conduct, to do part of what the institutions of a well-ordered society would do, and because it is also up to us, in our political conduct, to fight energetically for a juster institutional setup? I am not sure what overarching criterion could be applied in this balancing exercise, and there is little in the arguments of this article that may be helpful 
on this issue. My hunch, however, is that the second set of considerations is bound to weigh far more heavily, at any rate for all those (probably you and certainly me among them) who are better off than they would be in a just society. One cannot consistently claim to be committed to a maximin conception of justice and complacently enjoy privileges one can only be granted because the institutional setup violates this conception. Even if Rawlsians need not be Christians in a well-ordered society, they may well, after all, have to be (something like) Christians in the real world.

Even in a hypothetical well-ordered society, however, it is not enough for Rawlsians to refrain from cheating their maximin institutions and from using their bargaining power in order to force redistribution down. They may not have to be Christians, but they will have to be patriots, in the limited sense of refusing to pull out of their society for the sake of collecting higher post-tax incomes elsewhere. Unless the members of our society - and also those of other societies - are patriotic in this sense, concern with maximin will force our institutions to pay large unjustified incentive payments to the holders of precious factors. There is, it must be conceded, one alternative to such a patriotic commitment. It consists in hoisting the maximin institutions from the local to the global level, from the nation state to the world community. This is not, however, the way Rawls (1993b) himself conceives of global justice. The just law of peoples, in his view, is not the one on which the representatives of individuals would settle in a global original position in which they ignore which society they belong to. It is one on which the representatives of wellordered societies would settle behind a suitably redesigned veil of ignorance, and it will include no stronger redistributive institution than mutual aid in the event of famines and other disasters. But if this is the way Rawlsians need to conceive of global justice, then, as the world market strengthens its grip on a growing number of countries, it becomes every day more crucial that Rawlsians should also be patriots. In so far as Rawlsianism rejects the global maximin of a world society while at the same time shying away from patriotism, it can only turn into the ideological justification of a world-wide breakdown of redistributive institutions in the name of maximin constrained by free exit. ${ }^{9}$ And even if the global maximin is recognized, as I believe it

9 Rawls $(1990, \S 26.5 ; 1993 b)$ speaks of a "suitably qualified right of emigration". But the qualifications he has in mind have nothing to do with the patriotic duty advocated here: "I 
should, as the only coherent long-term ideal, patriotic commitments would provide a welcome help to relieve pressure on each country's (or each region's or each confederation's) redistributive setup in the long interim period that is bound to elapse before sufficiently powerful interpersonal transfer systems can be introduced at the global level.

Hence, whether or not consistent Rawlsians can stop short of advocating a global maximin, patriotism is a central ingredient in the individual ethics called forth by the conception of justice they assert.

Université catholique de Louvain Chaire Hoover d'éthique économique et sociale 3 Place Montesquieu, B-1348 Louvain-la-Neuve, Belgium certain sufficiently serious crimes may not be allowed to emigrate, pending serving their sentence" (Rawls 1990, §26.5, n 15). 


\section{References}

Baker, John. 1988. Arguing for Equality. London: Verso.

Baker, John. 1992. An egalitarian case for basic income. In Arguing for Basic Income. Ethical Foundations for a Radical Reform Ed. P. Van Parijs. London: Verso, 101-27.

Barry, Brian. 1989. Theories of Justice. London: Harvester-Wheatsheaf.

Barry, Brian. 1992. Equality Yes, Basic Income No. In Ed. P. Van Parijs. Arguing for Basic Income. Ethical Foundations for a Radical Reform. London: Verso, $128-40$.

Carens, Joseph H. 1981. Equality, Moral Incentives and the Market. Chicago: University of Chicago Press.

Carens, Joseph H. 1985. Compensatory justice and social institutions. Economics and Philosophy 1: 39-67.

Carens, Joseph H. 1986. Rights and duties in an egalitarian society. Political Theory 14 (1): 31-49.

Cohen, G.A. 1992a. Incentives, Inequality and Community. In The Tanner Lectures on Human Values Vol. XIII. Salt Lake City: University of Utah Press, 261-329.

Cohen, G.A. 1992b. The Pareto Argument for Inequality. Oxford: All Souls College, June 1992, 56 p.

Ezorsky, Gertrud. 1981. On Refined Utilitarianism. Journal of Philosophy 78: 1569.

Grey, Thomas C. 1973. The First Virtue. Stanford Law Review 25: 286-327.

Meade, James E. 1973. Theory of Economic Externalities. Leiden: Sijthoff.

Narveson, Jan F. 1976. A Puzzle about Economic Justice in Rawls's Theory. Social Theory and Practice 4: 1-27. 
Rawls, John. 1990. Justice as Fairness. A Restatement. Harvard University, unpublished lecture notes.

Rawls, John. 1993a. Political Liberalism. New York: Columbia University Press.

Rawls, John. 1993b. The Law of Peoples. Amnesty International Lecture, Oxford University, 12 February 1993.

Scanlon, Tim M. 1991. The Moral Basis of Interpersonal Comparisons. In Eds. J. Elster \& J.E. Roemer. Interpersonal Comparisons of Well-being . Cambridge: Cambridge University Press, 17-44.

Ten, C.L. 1980. Mill on Liberty. Oxford: Clarendon Press.

Van Parijs, Philippe. 1990. Equal Endowments as Undominated Diversity. Recherches Economiques de Louvain 56: 327-356.

Van Parijs, Philippe. 1991. Why Surfers Should be Fed. The liberal case for an unconditional basic income. Philosophy and Public Affairs 20: 101-31. 